\title{
A trainee's view of basic issues in audit*
}

\author{
Alastair Cook and Arturo Langa
}

\begin{abstract}
The evaluation of medical practice dates back many centuries. However, the concept of systematic medical audit is relatively modem. It is recognised that audit of every area of health services (including that of trainee's work and training) has been taking place. This article briefly discusses some of the basic issues in oudit, which include the principles, levels and types of audit, from a trainee's point of view.
\end{abstract}

The evaluation of medical practice goes back to at least $450 \mathrm{BC}$ when Heroditus commented on the quality of medical services in ancient Egypt. While responsible doctors have always tried to evaluate the services they provide and treatments they prescribe, the concept of systematic medical audit is relatively modern. In the 1970s the Department of Health felt that medical audit was too radical an idea for politicians to promote. The recognition in the last 15 years that health resources are limited means there is now a requirement to justify expenditure on investigation and treatment. The government White Paper Working for Pattents (Department of Health, 1989) suggested a framework for medical audit in hospital practice. It also recommended participation by all doctors in audit by 1991. This apparent imposition of audit by government has meant that there has been a tendency to view audit with suspicion - it can be seen as a means to justify cost cutting, or as a threat to the clinical freedom of doctors working within the NHS. Despite these suspicions, doctors have tried to take the lead in defining and structuring audit to make it a clinically useful exercise. The Royal College of Psychiatrists has now set up a special committee for audit and information technology which has the remit to try and agree national standards for audit which can be used at a local level. The requirement to take part in auditing activities raises a number of issues for trainees. Might there be an increase in workload? Will we have to change the way we record our activities? Where do we learn the skills required

* Dr Cook is Trainee Representative on the Special Committee for Audit and Information Technology. The views expressed in this paper are those of the authors themselves. for audit? What types of audit can trainees do themselves? In this article we have attempted to pull some of the most important definitions and principles of audit from the literature and to look at what these might really mean to trainees.

\section{Definitions and principles of audit}

The White Paper Working for Patients defines audit as "The systematic, critical analysis of medical care, including the procedures used for diagnosis and treatment, the use of resources, and the resulting outcome and quality of life for the patient". In other words, audit is used to assess the impact of every aspect of health care on the patient and also gauge the cost of this care. Every aspect of a trainee's work, and indeed the quality of their training itself, seems to be covered by this definition. Audit can be used to look at the structure of a service. This might mean examining the quality of facilities, looking at the numbers of staff and skills available or whether there are enough out-patient clinics.

Audit can be used to look at the process of a patient's episode of care. This might mean looking at the route patients takes to be admitted to hospital, the type of investigation and treatment they receive while in care and also the planning which goes into their discharge from care. Audit can also be used to look at the outcome of care, both in terms of the impact on patients' lives and also on the impact of that patient's care on the resources of the service.

Shaw \& Costain (1989) suggested seven basic principles for medical audit as follows.

1. Health authorities and medical staff should define explicitly their respective responsibilities for the quality of patient care. Medical staff can take responsibility for the provision of care only within a structure which must be resourced by health authorities. The responsibilities falling on trainees should also be explicitly defined.

2. Medical staff should organise themselves in order to fulfil the responsibility for audit and for taking action to improve clinical performance. Medical staff should 
organise their own audit as we are best placed to assess its clinical value. Trainees may get involved in helping to organise local audit but overall responsibility for organisation should be left to senior colleagues.

3. Each hospital and speciality should agree a regular programme of audit in which doctors of all grades participate. Trainees have to participate, but equally the most senior clinicians must allow their practice to be evaluated. Doctors in non training grades are also expected to participate in audit although there may be practical difficulties in this. One of the concepts of audit is that there is always room for improvement no matter how good a service might seem.

4. Process of audit should be relevant, objective, quantifiable, repeatable and able to effect appropriate change in organisation of the service and clinical practice. There is no point in doing audit for its own sake. Only if sound methods are used can useful results be achieved. For trainees, this means projects which must be well designed and manageable within the constraints put upon them. Projects will be more likely to be successfully completed if they can be seen as having real value for trainees.

5. Clinicians should be provided with the resources for medical audit. Good audit will require time and may also require some extra resources such as secretarial time, or for sending out questionnaires or using rating scales. Trainees involved in audit will need both time and access to such resources.

6. The process and outcome of medical audit should be documented. Someone has to produce something at the end. It is therefore important that trainees involved in the work also become involved in the reporting of projects. The prospect of producing results that will be useful is likely to help maintain momentum in such projects.

7. Medical audit should be subject to evaluation. The quality of audit needs, itself, to be audited from time to time. The way in which audit is carried out in a certain area can always be improved upon. It is important that data collected for audit be analysed using scientific methods.

\section{Levels and types of audit}

Audit will occur at a number of levels. National audit, such as the Royal College of Psychiatrists'
ECT audit, is unlikely to involve trainees in anything more than filling in forms from time to time. Regional audits are most likely to occur in the more specialised areas, such as child and adolescent or forensic psychiatry. Trainees in such specialties may have opportunities to design an audit at this level although this is more likely to be something which will involve senior registrars in the relevant specialty rather than junior trainees.

It is at a local level, between hospitals or in clinical meetings, that trainees are most likely to have an opportunity to get involved in audit. It has been suggested (Lelliot, 1992) that four types of audit can occur:

1. Medical audit - this is a review of purely medical procedure. Trainees might look at the time taken to send discharge letters, or the indications for prescription of a certain neuroleptic. This type of audit is usually the simplest for trainees to get involved with and can frequently be the most valuable.

2. Clinical audit - multidisciplinary review of service provided by health care team. If there is a form for multidisciplinary audit within the hospital concerned, trainees might become involved in looking at the outcome of an entire care package for particular patients.

3. Needs based audit - assessing the extent to which a service meets the needs of its users, or what impact groups of users have on available resources. This will usually mean sending questionnaires to patients in the hope of establishing which parts of the service are most valued by them. For trainees to do such an audit would require a great deal of support in terms of resources as well as in questionnaire design.

4. Service planning audit - systematic review of the current usage of components of a service. If there are accurate hospital information systems these can often give valuable data about routes of admission to hospital, or types of referrals made to their team.

Medical or clinical audit, together with needs based patient satisfaction audit, should provide an effective evaluation of a current service, while needs based audit and service planning audits would require to be combined to provide necessary estimates for the future provision of services. Most clinicians would agree the process of audit should follow 'audit cycle' (Mitchell \& Fowkes, 1985) involving standard setting, comparison of practice with standards, then attempts to improve practice. Emphasis is placed on the importance of 'closing the audit loop', with 
new standards being set or practice rechecked against accepted standards where areas of concern have been identified. This can create difficulties for trainees because of frequent moves of job. 'Closing the audit loop' may mean repeating the examination of data in six months or a year which will usually mean projects being started by one person and finished by another. It would be preferable for trainees to try and get involved in projects which they could finish themselves.

\section{Practical issues for trainees}

In practice all professions will find it difficult to incorporate audit into already busy schedules. The Royal College of Psychiatrists Working Party on Medical Audit (Royal College of Psychiatrists, 1989) recommended that every consultant be allowed to devote one session a week to audit. They made no recommendations for trainees. Experience suggests that activity for most is limited to lunch-time meetings, fortnightly or even monthly. A potential problem is that trainees will be asked to gather and collate the data requested by seniors for the next meeting. Unless protected time is allocated hurried, inaccurate data collection is likely to be the result.

In hospital practice trainees and doctors in non training grades are well placed to participate in audit activities. Usually trainees will be responsible for keeping case records, ordering investigations, and often initiating treatment. The degree of control or supervision by senior colleagues varies from speciality to speciality depending on the relative experience of trainees. Trainees are well placed to design and carry out small audit projects of their own.

It is important that trainees produce audit work of their own in areas of medical practice they find interesting. The support of consultants is required in finding ideas, helping design projects and at the stage of data collection. Most importantly, trainees require time allocated specifically to audit. The suggestion that valuable audit could be carried out on small amounts of data led to the comment that audit is no more than bad research. In fact the type of data examined in audit is likely to have a different emphasis to that of research, but all criteria on which good research is based can be equally applied in audit. The change in emphasis is the result of differences in the aims of audit and research. "Research is concerned with discovering the right thing to do; audit with ensuring it is done right" (Smith, 1992).

There is considerable pressure on junior doctors to produce research for career advancement. Many junior doctors are not academically oriented and find the prospect of full-time research, possibly in less clinical areas, unattractive. To such doctors, participation in audit may seem more clinically relevant than some research. For doctors training to be clinicians, experience of audit may come to be regarded as a valuable asset equal to much research.

\section{Conclusion}

The introduction of audit into clinical practice, although initially government led, has been accepted by doctors as something which can be clinically useful. The College is now taking an active role in promoting standards of audit at a national level. It is now recognised that there will be audit of every area of health services, including all aspects of trainees' work and training. Trainees will be well placed to carry out audit projects in all the areas in which they are working. For audit to be worthwhile, a project needs to be well designed and to be carried out by somebody with time and resources to do it. For trainees, this means effective back-up and specific time allocated to audit. If this is not available, it is likely to be unenthusiastically and sloppily done, leading to inaccurate figures which might cause further problems in themselves. While audit might be seen as an addition to trainees' workloads, there are potential benefits in that results should lead to improvements in practice. An interesting audit may lead to further projects or be worthy of publication itself. The combined inducements of educational value and potential career advancement may well spur trainees into making the most of what is a potentially valuable area for them.

\section{References}

DePaRTMENT OF HEALTh (1989) Working for Patients. London: HMSO.

FIRTH-COZENS, J. \& STORER, D. (1992) Registrar and sentor registrar's perceptions of their audit activities. Quality in Healthcare, 1, 161-164.

LELLIOT, P. (1992) The College Research Unit and its clinical audit programme. Psychiatric Bulletin, 16, 313-315.

MrTCHELL, F.G.R. \& FowkES, M.W. (1985) Audit reviewed: does feedback of performance change clinical behaviour? Journal of Royal College of Physicians, 19, 251-254.

Royal COLlEge OF PSYCHIATRISTS (1989) Preliminary report on medical audit. Psychiatric Bulletin. 13, 577-580.

SHAW, C.D. \& CostaIN, D.W. (1989) Guidelines for medical audit: seven principles. British Medical Journal. 289. 498-499.

SMrT, R. (1992) Audit and research. British Medical Journal, 305, 905-906.

Alastair Cook, Registrar, Lynebank Hospital; and *Arturo Langa, Sentor Registrar, Lynebank Hospital, Halbeath Road, Dunfermline, KY11 4UW

*Correspondence 